\title{
PERANCANGAN APLIKASI BERBASIS ANDROID UNTUK KOMUNITAS PENGGEMAR BURUNG KICAU
}

\author{
Albert V. Dian Sano ${ }^{1}$, Bintang Fadhli Muhammad ${ }^{2}$ \\ Edward Kristian Mangare ${ }^{3}$, Jeremy Jason ${ }^{4}$, Taufiq Hidayah ${ }^{5}$ \\ 1,2,3,4,5 Program Studi Ilmu Komputer Institut Teknologi Kreatif Bina Nusantara Malang, Indonesia \\ E-mail: avds@binus.ac.id ${ }^{1}$, bintang.muhammad@binus.ac.id ${ }^{2}$, edward.mangare@binus.ac.id ${ }^{3}$, \\ jeremy.jason@ binus.ac.id ${ }^{4}$, taufiq.hidayah@ binus.ac.id ${ }^{5}$
}

\begin{abstract}
Industry 4.0 is developing and industry 4.0 is the name of the latest automation and data exchange trends in manufacturing technology. This term covers physical-cyber systems, the internet for everything, cloud computing, and cognitive computing. Industry 4.0 produces "smart factories". Industry 4.0 can be seen from More than 50 percent or about 143 million people out of 262 million Indonesians have been connected to the internet throughout 2017, at least according to the latest report by the Indonesian Internet Service Providers Association. The problem in this research is not understanding the advantages and disadvantages of the birds owned and the level of extinction of birds owned. The purpose of this research is to design an Android-based application for the bird enthusiast community. Twitter is an android based forum for the bird lovers community. The application of Android technology to information about the activities of the birds chirping community is an application that serves to provide effective information for members of the chirping mania community at various events, competitions and buying and selling birds. In this application users can post photos of birds, bird trading transactions. see news and race schedule information and tips on bird care to be ready to compete. This application was built using Android Studio and uses Business Model Canvas (BMC) design methods, Use Cases, Activity Diagrams, and Mock-ups. The result can simplify the process of buying and selling birdsong, and makes it easier for community members to get information on various events related to birdsong.
\end{abstract}

Keywords: Technology, Internet, Applications, Android.

\begin{abstract}
ABSTRAK
Industri 4.0 sedang berkembang dan industri 4.0 adalah nama tren otomasi dan pertukaran data terkini dalam teknologi pabrik. Istilah ini mencakup sistem siber-fisik, internet untuk segala, komputasi awan, dan komputasi kognitif. Industri 4.0 menghasilkan "pabrik cerdas". Industry 4.0 dapat dilihat dari Lebih dari 50 persen atau sekitar 143 juta orang dari 262 juta orang Indonesia telah terhubung oleh jaringan internet sepanjang 2017, setidaknya begitu menurut laporan teranyar Asosiasi Penyelenggara Jasa Internet Indonesia. Permasalahan yang ada dalam penelitian ini yakni belum mengerti kekurangan serta kelebihan dari burung yang dimiliki dan tingkat kepunahan burung yang dimiliki. Tujuan dari penelitian ini adalah merancang aplikasi berbasis android untuk komunitas penggermar burung. Kicau adalah forum berbasis android untuk komunitas pecinta burung. Penerapan teknologi Android pada informasi tentang kegiatan komunitas kicau burung adalah aplikasi yang berfungsi untuk memberikan informasi yang efektif bagi anggota komunitas kicau mania di berbagai acara, kompetisi dan jual beli burung. Dalam aplikasi ini pengguna dapat memposting foto dari burung, transaksi jual beli burung. lihat informasi berita dan jadwal balapan serta tip tentang perawatan burung agar siap bersaing. Aplikasi ini dibangun menggunakan Android Studio dan menggunakan metode desain Business Model Canvas (BMC), Use Case, Activity Diagram, dan Mock-up. Hasilnya dapat mempermudah proses transaksi jual dan beli burung kicau, dan mempermudah para anggota komunitas untuk mendapatkan informasi berbagai acara terkait burung kicau.
\end{abstract}

Kata Kunci: Teknologi, Internet, Aplikasi, Android. 


\section{PENDAHULUAN}

Industri 4.0 sedang berkembang dan industri 4.0 adalah nama tren otomasi dan pertukaran data terkini dalam teknologi pabrik. Istilah ini mencakup sistem siber-fisik, internet untuk segala, komputasi awan, dan komputasi kognitif. Industri 4.0 menghasilkan "pabrik cerdas". Industry 4.0 dapat dilihat dari Lebih dari 50 persen atau sekitar 143 juta orang dari 262 juta orang Indonesia telah terhubung oleh jaringan internet sepanjang 2017, setidaknya begitu menurut laporan teranyar (Asosiasi Penyelenggara Jasa Internet Indonesia [APJII], 2017)

Awal dari perkembangan Industry 4.0 adanya internet yang menghubungkan berbagai perangkat antara satu perangkat ke perangkat yang lainnya dengan mudah dan cepat hanya melalui internet semua bisa dikendalikan secara jarak jauh lalu semakin lama semua akan serba otomatis dan itu juga yang memudahkan dalam pekerjaan manusia untuk dilakukan dengan aplikasi dan semua bisa dilakukan degan internet .

Penghobi burung sudah ada sejak tahun 1970 dan mempunyai pasar yang tidak terbatas, akan tetapi masalah yang timbul yakni belum mengerti kekurangan serta kelebihan dari burung yang dimiliki dan tingkat kepunahan burung yang dimiliki. Sementara kontes burung muncul ke dalam masyarakat karena banyaknya permintaan dari para penghobi burung yang ingin burung peliharaannya berprestasi dalam lomba (Bayu Sugihart, 2011).

Tujuan dari penelitian ini ialah untuk adalah merancang aplikasi berbasis android untuk komunitas penggermar burung. Kicau adalah forum berbasis android untuk komunitas pecinta burung. Penerapan teknologi Android pada informasi tentang kegiatan komunitas kicau burung adalah aplikasi yang berfungsi untuk memberikan informasi yang efektif bagi anggota komunitas kicau mania di berbagai acara, kompetisi dan jual beli burung. Dalam aplikasi ini pengguna dapat memposting foto dari burung, transaksi jual beli burung. lihat informasi berita dan jadwal balapan serta tip tentang perawatan burung agar siap bersaing.

Penelitian dari Dewa Reza Fauzy dengan judul Sistem Informasi Pengelolaan Kompetisi Burung Kicau Di Skm Kicau Berbasis Web. sistem pengelolaan kompetisi burung berbasis web ini dapat membantu petugas dalam pelaksanan tugasnya khususnya pada aktifitas pengelolaan pendaftaran peserta, juga membantu admin untuk mengolah data serta menunjang dalam pengambilan keputusan. Keuntungan sistem ini antara dapat memudahkan dalam proses pencatatan peserta lomba dan membantu peserta yang berada diluar kota untuk melakukan pendaftaran secara online.
Dalam pencatatan pembayaran perlombaan dan memudahkan dalam menghitung penerimaan pendapatan perlombaan, Dengan sistem berbasis website ini memudahkan SKM Kicau menyalurkan informasi tentang perlombaan yang ada di SKM Kicau, Diharapkan memudahkan kepada pengguna dalam mengelola data penilaian perlombaan dan penentuan pemenang lomba (Dewayana \& Budi, 2009).

Penelitian dari Ito Riris Immasari dan Erlina dengan judul Aplikasi Informasi Kicau Mania Depok Berbasis Android. Kicau Mania adalah suatu komunitas pecinta burung. Aplikasi pemanfaatan teknologi Android pada informasi kegiatan komunitas burung berkicau ini merupakan aplikasi yang berfungsi untuk memberikan informasi yang efektif bagi anggota komunitas kicau mania dalam berbagai acara dan lomba yang diadakan di sekitar wilayah Depok, dalam aplikasi ini user dapat melihat informasi jadwal lomba, tips perawatan burung dan master suara untuk melatih burung agar siap berlomba. Aplikasi ini dibangun menggunakan Android Studio dan menggunakan metode perancangan Unified modelling language (Ito Riris Immasari dan Erlina, 2017).

Pembaharuan dalam penelitian ini adalah Aplikasi ini dibangun menggunakan Android Studio dan menggunakan metode desain Business Model Canvas (BMC), Use Case, Activity Diagram, dan Mock-up (Solihah Elus, 2014) .

Peran "Kicau Mania" sebutan untuk penggemar kontes burung sangatlah penting pada saat perlombaan atau kontes burung berlangsung. Dengan adanya para "Kicau Mania" tersebut dapat terlihat hidupnya suatu kontes dengan ramainya lokasi yang digunakan untuk kontes burung. Pemelihara burung di Indonesia telah berhasil menggerakkan perekonomian kerakyatan. Angkanya fantastis, mencapai Rp 1,7 triliun per tahun. berdasarkan laporan, spesies burung di Indonesia mencapai 1.660-an (Yohanes Paulu Sutejo, 2012).

\section{METODE PENELITIAN}

\section{Identifikasi Kebutuhan Pengguna}

Melalui requirement modeling, kami berusaha untuk memahami kebutuhan pengguna. Berikut tahapan-tahapan untuk menentukan semua requirement-nya :

\section{1) Inception}

Pada tahap pertama ini, kami melakukan pengamatan terhadap masalah - masalah nyata yang terlihat dimasyarakat dan kemudian kami berusaha mengerti masalah tersebut. 
2) Elicitation

Selesai dari inception, pada tahapan ini kita berusaha untuk mengambil sejumlah pendapat dari target user. Kami menanyakan kebutuhan/requirement-requirement apa saja yang dibutuhkan mereka.

3) Elaboration

Pada tahap ini, kami telah mengetahui berbagai requirement yang telah diajukan oleh target user. Kemudian, kami mengerjakan secara detail berdasarkan pada requirementrequirement yang sudah kami dapatkan dari tahapan sebelumnya. Pada tahap ini kami melakukan analisi untuk memahami segala aspek-aspek requirement yang kami terima dari target user.

4) Negotiation

Pada tahap ini dilakukan negosiasi dengan tim dan pihak investor. Disini kami menyepakati bagaimana nantinya sistem aplikasi ini berjalan dan yang diinginkan.

5) Specification

Pada tahap ini kami lebih detail lagi dalam mendefinisikan requirement yang sudah diterima, menggunakan diagram-diagram seperti: Unified Modeling Language (UML) diagram. Penggunaan diagram memudahkan developer untuk mengerti apa yang diinginkan customer dan mempermudah proses pembangunan aplikasi tersebut.

6) Validation

Sesuai dengan judul bagian ini, kami melakukan validation atau peninjauaan kembali apakah aplikasi kami sudah sesuai dengan requirement dari target user atau belum. Kemudian, pada tahap ini juga dilakukan testing atau pengecekan untuk mengetahui apakah ada bug eror atau tidak.

7) Requirements Management

Tahap terakhir, kami selaku developer terus melakukan manajemen requirement untuk berjaga - jaga ketika terjadinya perubahan oleh target user.

\section{HASIL DAN PEMBAHASAN}

Ada banyak situasi dimana pemodelan requirements berbasis teks mungkin tidak memberikan informasi yang jelas dan singkat. Dalam banyak hal, penyajian secara diagramatis bisa mempermudah pemahaman dalam pengembangan sistem terlebih lagi untuk sistem yang kompleks. Dalam perancangan sistem dalam kajian ini akan digunakan use-case diagram, activity diagram, dan perancangan antarmuka pengguna.

\section{Use case Diagram}

Use-case diagram bisa untuk menentukan fungsionalitas dan fitur-fitur aplikasi dari sudut pandang pengguna. Gambar 2 adalah use-case diagram yang menjelaskan fungsi dan fitur dari sistem yang didapatkan dari hasil requirement modeling pada tahap sebelumnya. Jadi, karena diagram tersebut menampilkan semua use case, diagram tersebut sangat membantu untuk memastikan apakah semua fungsionalitas sistem sudah tercantum atau belum.

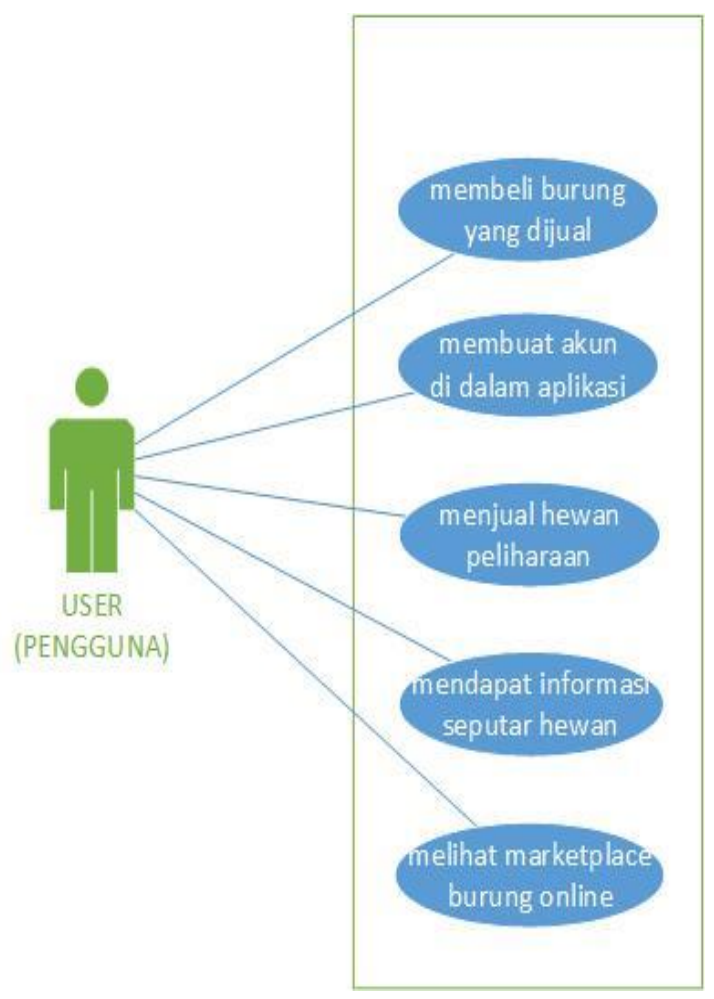

Sumber : (Albert V. Dian Sano \& Edward Kristian Mangare, Jeremy Jason, 2019)

Gambar 1. Use-case diagram untuk prototipe aplikasi berbasis android "Kicau".

Penjelasan use-case diagram pada gambar 2:

1. Membuat akun di dalam aplikasi agar user dapat terdaftar kedalam aplikasi dengan gratis dan bisa mengakses fitur jika sudah memenuhi syarat.

2. Menjual burung ke dalam aplikasi dengan mudah dan cepat untuk menyebarkan.

3. Membeli burung lewat perantara aplikasi karena di dalam aplikasi memiliki marketplace khusus burung kicau.

4. Melihat marketplace burung kicau di aplikasi.

5. Mendapat berita dan informasi yang bermanfaat untuk penghobi burung kicau. 


\section{Activity Diagram}

Activity diagram bisa membantu menjelaskan dinamika perilaku sistem atau bagian dari istem melalui aliran kontrol antara berbagai tindakan yang dilakukan oleh sistem. Gambar 3 menyajikan activity diagram untuk aplikasi berbasis android dalam kajian ini (nama aplikasi adalah "Kicau").

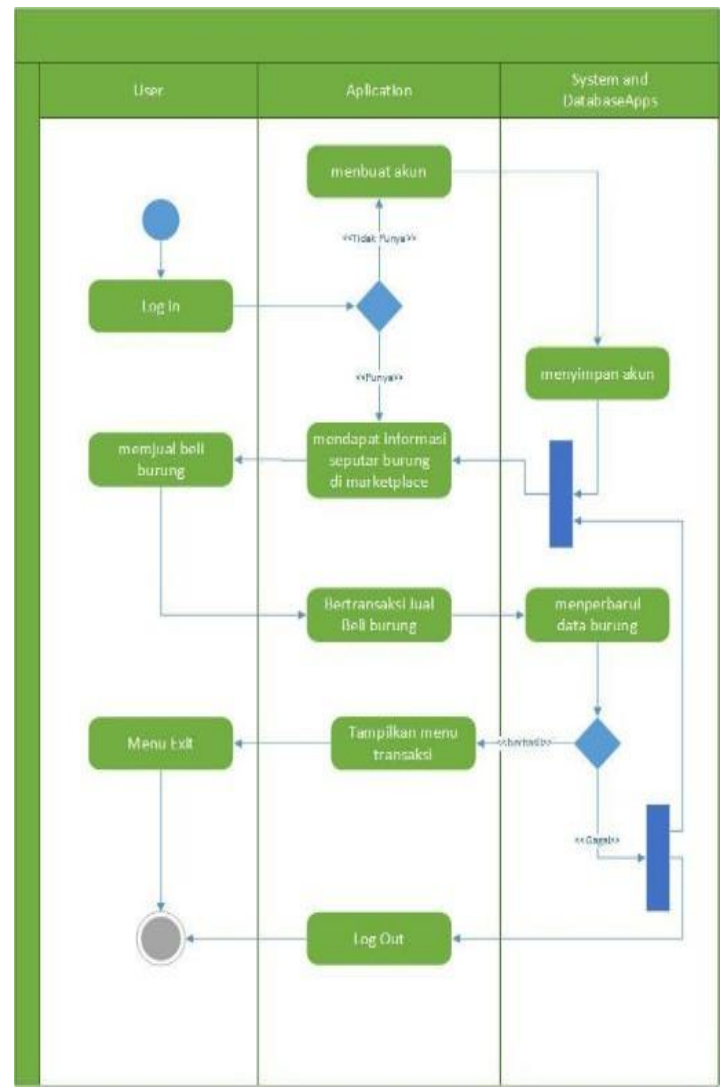

Sumber : (Albert V. Dian Sano \& Edward Kristian Mangare, Jeremy Jason, 2019)

Gambar 2. Activity Diagram prototipe aplikasi berbasis android "Kicau"

\section{Perancangan Antarmuka}

Antarmuka boleh dibilang merupakan elemen yang paling penting dari suatu produk apapun berbasis komputer. Jika antarmuka dirancang dengan sembarangan, maka berpotensi menyebabkan kegagalan aplikasi sebagai sistem produk.

Perancangan antarmuka pada aplikasi dalam kajian ini menerapkan tiga pedoman dasar yang paling penting yaitu:

1. Menempatkan pengguna sebagai pemegang kendali.

2. Mengurangi load memori pengguna.

3. Antarmuka yang konsisten.

Untuk menerapkan ketiga prinsip tersebut, dalam kajian ini akan mengadopsi panduan dalam framework material design android. Implementasi dari hasil mengadopsi framework tersebut dalam kajian ini adalah penerapan teknik recyclerview dalam antarmuka pengguna dan bottom navigation bar. Penerapan recyclerview akan bertujuan untuk mengurangi beban memori sistem. Bottom navigation bar bertujuan mengadopsi kebiasaan pengguna yang berinteraksi dengan aplikasi berbasis mobile menggunakan satu tangan.

Gambar 6,7,8 adalah screenshot mock up yang menyajikan ketiga prinsip dasar dalam perancangan antarmuka dengan mengadopsi framework material design untuk aplikasi berbasis android. Sementara gambar 4 adalah splash screen yang bertujuan untuk meningkatkan efek psikologis kebahagiaan pengguna dengan penerapan animasi singkat sebelum menu login pada gambar 3 .

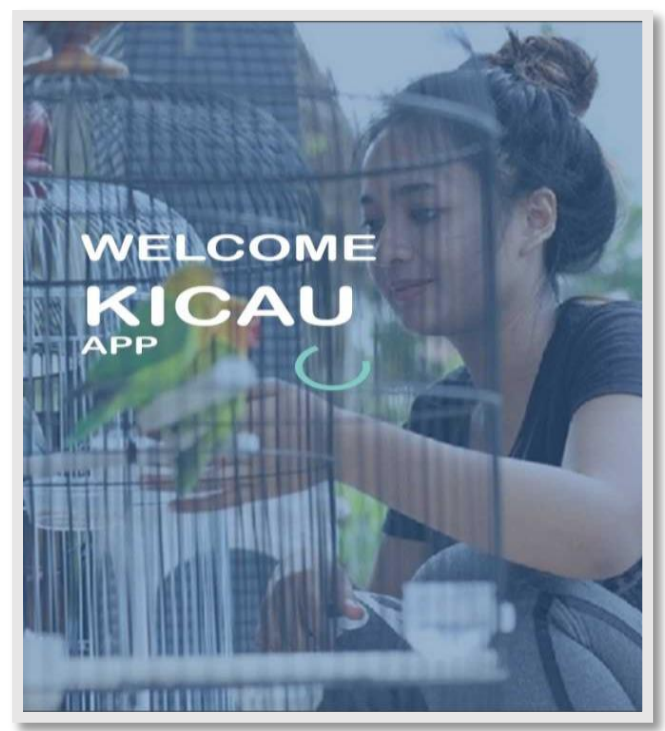

Sumber : (Albert V. Dian Sano \& Edward Kristian Mangare, Jeremy Jason, 2019)

Gambar 3. Splash screen prototipe aplikasi berbasis android "Kicau"

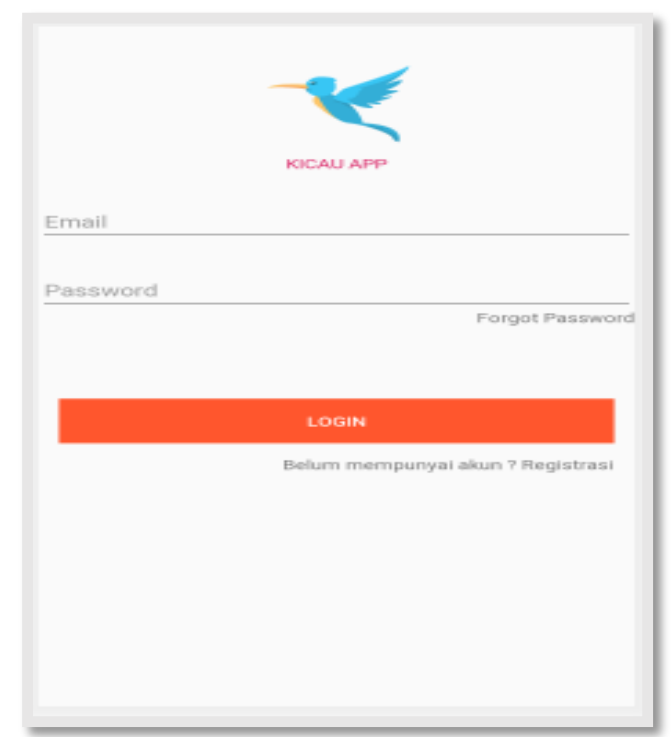

Sumber : (Albert V. Dian Sano \& Edward Kristian Mangare, Jeremy Jason, 2019)

Gambar 4. Menu login prototipe aplikasi berbasis android "Kicau" 

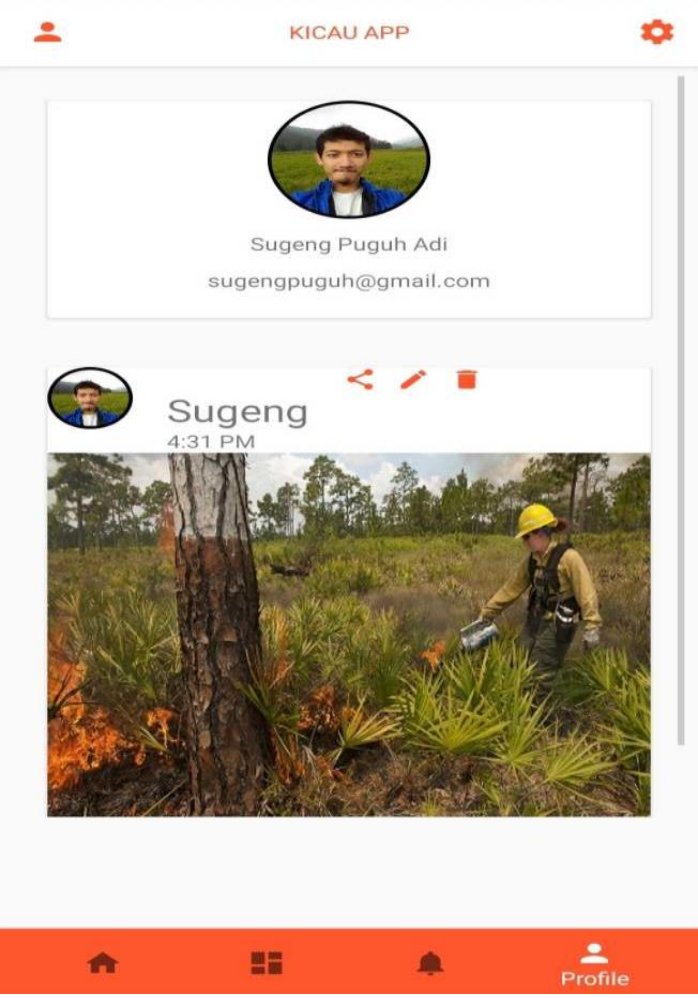

Sumber : (Albert V. Dian Sano \& Edward Kristian Mangare, Jeremy Jason, 2019)

Gambar 5. Menu Home prototipe aplikasi berbasis android "Kicau" yang mengimplementasikan recyclerview dan bottom navigation bar.

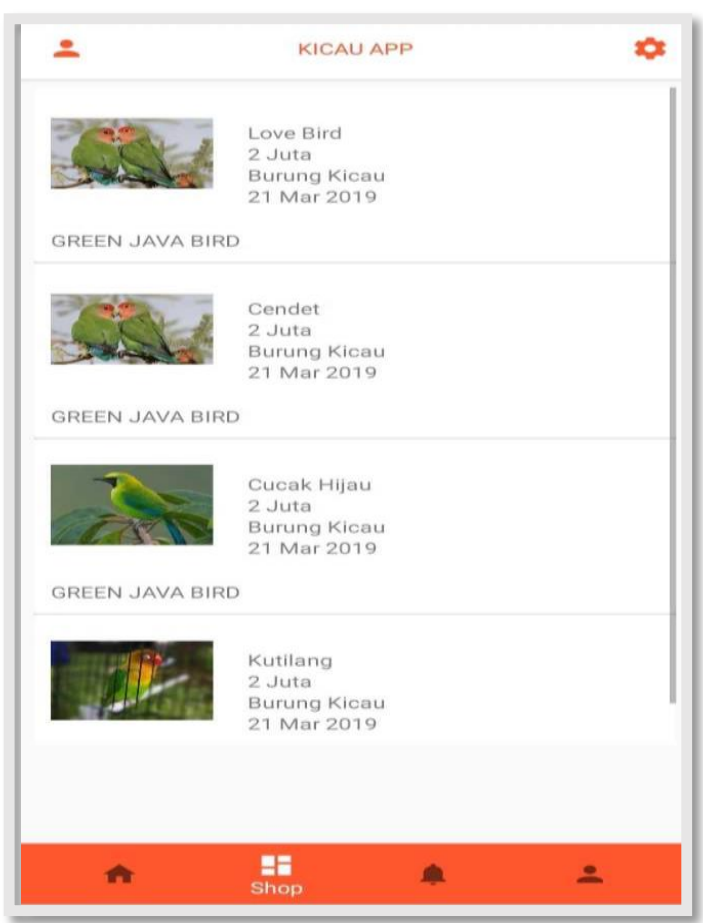

Sumber : (Albert V. Dian Sano \& Edward Kristian Mangare, Jeremy Jason, 2019)

Gambar 6. Menu Shop prototipe aplikasi berbasis android "Kicau" yang mengimplementasikan recyclerview dan bottom navigation bar.

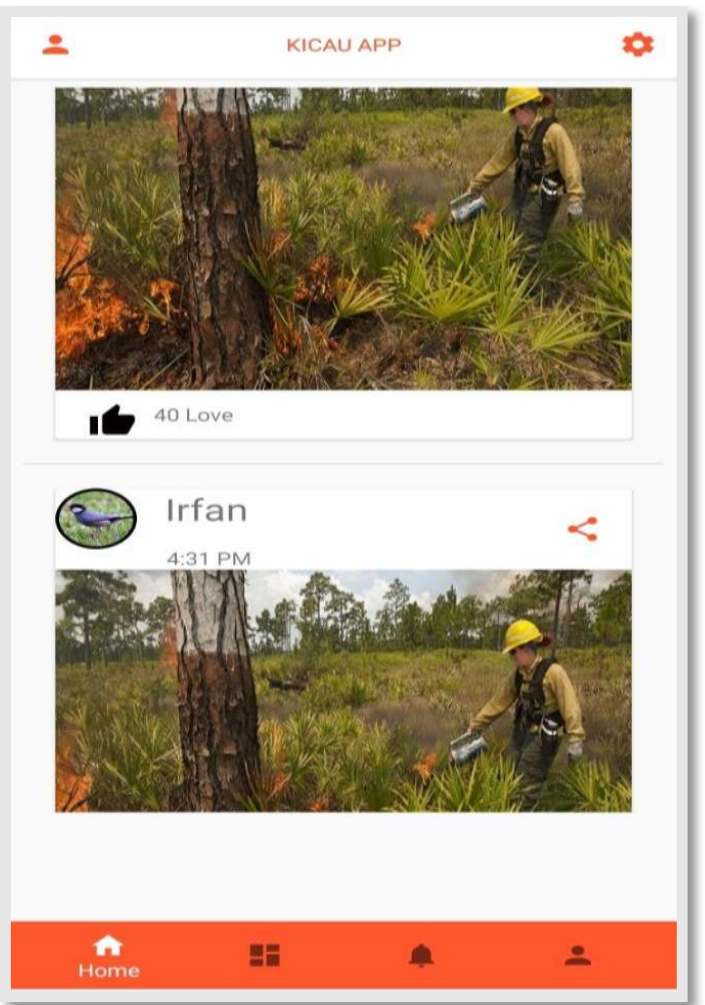

Sumber : (Albert V. Dian Sano \& Edward Kristian Mangare, Jeremy Jason, 2019)

Gambar 7. Menu Event prototipe aplikasi berbasis android "Kicau" yang mengimplementasikan recyclerview dan bottom navigation bar.

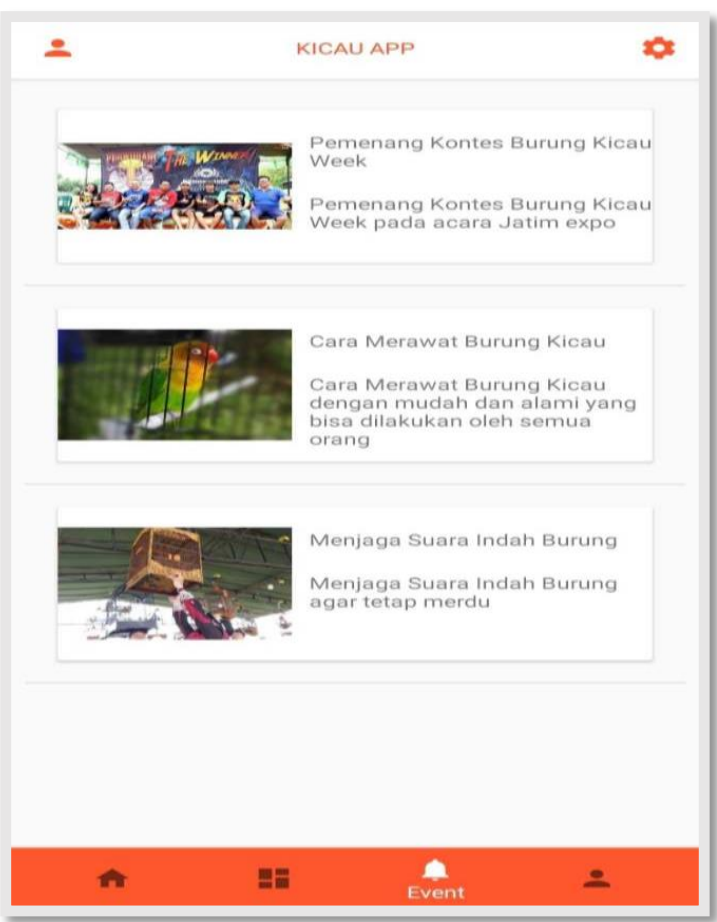

Sumber : (Albert V. Dian Sano \& Edward Kristian Mangare, Jeremy Jason, 2019)

Gambar 8. Menu Profile prototipe aplikasi berbasis android "Kicau" yang mengimplementasikan recyclerview dan bottom navigation bar. 


\section{KESIMPULAN}

Perancangan aplikasi berbasis Android untuk komunitas penggemar burung ini diharapkan mampu menjadi solusi bagi beberapa problem yang diidentifikasi sebelumnya, yaitu menjadi penghubung antar sesama penggemar burung kicau, mempermudah proses transaksi jual dan beli burung kicau, dan mempermudah para anggota komunitas untuk mendapatkan informasi berbagai acara terkait burung kicau

\section{DAFTAR PUSTAKA}

Albert V. Dian Sano, B. F. M., \& Edward Kristian Mangare, Jeremy Jason, T. H. (2019). Perancangan Aplikasi Berbasis Android Untuk Komunitas Penggemar Burung Kicau. Asosiasi Penyelenggara Jasa Internet Indonesia [APJII]. (2017). Profil Pengguna Internet Indonesia. Asosiasi Penyelenggara Jasa Internet Indonesia [APJII].
Bayu Sugihart. (2011). Mencetak Perkutut Juara. Argomedia Pustaka.

Dewayana, T., \& Budi, A. (2009). Pemilihan Pemasok Cooper ROD Menggunakan Metode ANP (Studi Kasus : PT. Olex Cables Indonesia (OLEXINDO)). J@Ti Undip, IV(3), 212-217.

Ito Riris Immasari dan Erlina. (2017). Aplikasi Informasi Kicau Mania Depok Berbasis Android. 1(1), 57-69.

Solihah Elus. (2014). Analisis Model Bisnis Pada KNM Fish Farm dengan Pendekatan Business Model Canvas (BMC). 2 No 9.

Yohanes Paulu Sutejo. (2012). Strategi Komunikasi Komunitas dalam Mempertahankan Solidaritas (Studi Pada Komunitas Kicau Mania Salatiga). Fakultas Ilmu Sosial dan Ilmu Komunikasi Universitas Kristen Satya Wacana. Salatiga. 